\title{
Nanosecond Electric Pulses Induce Early and Late Phases of DNA Damage and Cell Death in Cisplatin-Resistant Human Ovarian Cancer Cells
}

\author{
Guanhua Qian and Tinghe Yu \\ Key Medical Laboratory of Obstetrics and Gynecology, The Second Affiliated Hospital, Chongqing Medical University, \\ Chongqing, China \\ Correspondence should be addressed to Tinghe Yu; yutinghe@hotmail.com
}

Received 1 May 2018; Revised 26 June 2018; Accepted 11 July 2018; Published 8 August 2018

Academic Editor: Ermanno Greco

Copyright (C) 2018 Guanhua Qian and Tinghe Yu. This is an open access article distributed under the Creative Commons Attribution License, which permits unrestricted use, distribution, and reproduction in any medium, provided the original work is properly cited.

\begin{abstract}
Chemoresistance is a challenge for management of ovarian cancer, and therefore the response of resistant cells to nanosecond electric pulses (nsEP) was explored. Human ovarian cancer cell line COC1 and the cisplatin-resistant subline COC1/DDP were subjected to $\mathrm{nsEP}(32 \mathrm{~ns}, 10 \mathrm{kV} / \mathrm{cm}, 10 \mathrm{~Hz}$ pulse repletion frequency, and $10 \mathrm{~min}$ exposure duration), and then the cellular responses were followed. The percentages of dead cells and of comet-formed cells in the alkaline assay displayed two peak levels (i.e., 2 and $8 \mathrm{~h}$ after nsEP exposure), with the highest value noted at $8 \mathrm{~h}$; the percentage of comet-formed cells in the neutral assay was increased at $8 \mathrm{~h}$; the apoptotic percentage was increased at $8 \mathrm{~h}$, with collapse of the mitochondrial membrane potential and the activation of caspase- 3 and caspase-9. The comet assay demonstrated DNA single-strand break at $2 \mathrm{~h}$ and double-strand break at $8 \mathrm{~h}$. nsEP resulted in lower cytotoxicity in COC1/DDP cells compared with COC1 cells. These findings indicated that nsEP induced early and late phases of DNA damage and cell death, and these two types of cell death may have distinct applications to treatments of chemoresistant ovarian cancers.
\end{abstract}

\section{Introduction}

Chemoresistance is yet a challenge for management of ovarian cancer; a chemical sensitizer lacks selectivity, resulting in poor therapeutic efficacy and toxicity to noncancerous tissues [1]. A physical modality may be an alternative because the energy can be delivered into the preselected volume without harming adjacent tissues, realizing a targeted treatment [2].

Nanosecond electric pulses (nsEP) can trans-membranously evoke a high potential (i.e., $>0.5-1.0 \mathrm{~V}$, the critical potential required to cause damage) in specifically subcellular structures, thereby causing responses such as membrane poration, ion permeation, and protein modification [3-7]. These effects to a certain extent will lead to cell death mainly via inducing apoptosis [5-7]. However, the responsive difference between chemosensitive and chemoresistant cells remains unclear.

Theoretical calculations based on the multilayer dielectric model have manifested that nsEP $(24 \mathrm{~ns}, 6 \mathrm{kV} / \mathrm{cm})$ can evoke potentials of $1.98 \mathrm{~V}$ in the nucleoplasm, $1.17 \mathrm{~V}$ in the cytoplasm, and $0.25 \mathrm{~V}$ in the cellular membrane, in cisplatinresistant human ovarian cancer cells COC1/DDP [4]. The high potential in the nucleoplasm leads to DNA singlestrand break (SSB). The data suggest that nsEP may be a therapeutic strategy for resistant cancers, considering the pivotal role of DNA damage and repair in chemoresistance [8, 9]. However, the biological implications of the high potential in the cytoplasm remain unclear.

Here we compared the response to nsEP between cisplatin-sensitive and -resistant human ovarian cancer cells. Data indicated that nsEP can induce early and late phases of cell death in chemoresistant cells. These two types of cell death may have distinctly therapeutic applications.

\section{Materials and Methods}

2.1. Cells. Human ovarian cancer cell line $\mathrm{COCl}$ and the cisplatin-resistant subline COC1/DDP (China Center for Typical Culture Collection, Wuhan, China) were cultured in suspension in RPMI 1640 medium (Hyclone, Beijing, China) 
supplemented with $10 \%$ fetal bovine serum (Hyclone), at $37^{\circ} \mathrm{C}$ and $5 \% \mathrm{CO}_{2}$ [10]. Cisplatin $(0.5 \mu \mathrm{g} / \mathrm{ml})$ was added to the COC1/DDP medium to maintain the resistant property; cells were transferred into drug-free medium for $>48 \mathrm{~h}$ before experiments to avoid interferences due to residual cisplatin [2]. The single-cell suspension was prepared and the concentration was adjusted to $1.0 \times 10^{6}$ cells $/ \mathrm{ml}$.

2.2. nsEP Exposure. nsEP treatments were performed as described previously using a device designed by School of Physics, University of Electronic Science and Technology of China (Chengdu, China) [4]. $2.0 \mathrm{ml}$ of single-cell suspension was subjected to nsEP. The pulse duration was $32 \mathrm{~ns}$ at a $10 \mathrm{~Hz}$ pulse repetition frequency, the strength was $10 \mathrm{kV} / \mathrm{cm}$, and the total exposure time was $10 \mathrm{~min}$. nsEP-treated cells were maintained at $37^{\circ} \mathrm{C}$ before assays. Control cells received sham exposure.

2.3. Cell Death. Cell viability was determined with a WST-8 assay (Dojindo Lab., Kumamoto, Japan) after 2, 4, 8, 12, and $24 \mathrm{~h}$, and then the percentage of dead cells was calculated ([1 - (absorbance in treated cells/absorbance in control cells @ $2 \mathrm{~h})] \times 100 \%)[11]$.

2.4. DNA Damage. DNA damage was detected with the alkaline comet assay after $2,4,8,12$, and $24 \mathrm{~h}$, and cells at 2 and $8 \mathrm{~h}$ also received the neutral comet assay to determine whether there was double-strand break (DSB) [12]. The percentage of comet-formed cells was used to quantify the degree of DNA damage [(number of comet-formed cells/number of total cells) $\times 100 \%$ ] [13]. Control cells served as the reference considering a high sensitivity of the comet assay: a percentage of $<5 \%$ demonstrated no unspecific cellular damage, thereby avoiding an overestimation.

2.5. Apoptosis. Cell apoptosis was analyzed with the Annexin $\mathrm{V}$ assay (Nanjing Keygen Biotech., Nanjing, China) after 2 and $8 \mathrm{~h}$. Cells were stained with FITC-Annexin V and propidium iodide (PI) and then received flow cytometry. The $\mathrm{V}^{+} / \mathrm{PI}^{-}$population represented early apoptotic cells, the $\mathrm{V}^{+} / \mathrm{PI}^{+}$population was regarded as late apoptotic cells, and the sum was the number of total apoptotic cells [14].

2.6. Mitochondrial Membrane Potential. The membrane potential was determined by fluorospectrophotometry using the JC- 1 assay (Invitrogen, Eugene, OR) after 2 and $8 \mathrm{~h}$ [15]. $\lambda_{\text {ex }}$ was $485 \mathrm{~nm}$, and $\lambda_{\text {em }}$ was 529 or $590 \mathrm{~nm}$. The ratio of red to green fluorescence intensity reflected the membrane potential $[10,15]$. Cells were also observed under a fluorescence microscopy.

2.7. Activity of Caspase-3 and Caspase-9. Activity of caspase3 and caspase- 9 was determined using a luminescent assay (Promega, Madison, WI) after 2 and 8 h. The lg[RLU] (relative light unit) reflected the enzymatic level.

2.8. High Mobility Group Box 1 (HMGB1). HMGB1 in the culture supernatant, the biomarker of cell necrosis, was detected with an enzyme-linked immunosorbent assay (Shino-Test, Kanagawa, Japan) after 2 and 8 h [16].

2.9. Temperature Rise. Theoretical simulations suggested that multiple pulses may cause Joule heating [17]. In order to determine whether heat played a part in the cellular response, the temperature rise in the cell suspension was measured using a thermocouple immediately after nsEP exposure (Guangzhou Sungun Meas. Ctrl. Technol. Co., Ltd., Guangzhou, China) [18].

2.10. Statistics. Data were processed with the SAS software (SAS Inst., Cary, NC). Analysis of variance was used and multiple comparisons were corrected with the Student-NewmanKeuls test. The critical value was set at $\mathrm{p}<0.05$.

\section{Results and Discussion}

3.1. Cell Death and DNA Damage Displayed Two Peak Levels at 2 and $8 \mathrm{~h}$, but Apoptosis Was Detected Only at $8 \mathrm{~h}$. The percentage of dead cells was increased after nsEP treatments in both cell lines, with 2 peak levels noted at 2 and $8 \mathrm{~h}(\mathrm{p}<0.0001, \mathrm{p}<0.0001)$. Values were $20.3 \pm 0.1 \%$ and $11.3 \pm 0.0 \%$ at $2 \mathrm{~h}(\mathrm{p}<0.0001)$, and $36.4 \pm 2.7 \%$ and $23.1 \pm 1.2 \%$ at $8 \mathrm{~h}(\mathrm{p}=0.0106)$, in COC1 and COC1/DDP cells, respectively (Figure 1(a)).

The percentage of comet-formed cells in the alkaline assay displayed a similar trend in both cell lines: the peak value was noted at 2 and $8 \mathrm{~h}(\mathrm{p}<0.0001, \mathrm{p}<0.0001)$. Levels were $26.3 \pm 1.3 \%$ and $18.2 \pm 0.5 \%$ at $2 \mathrm{~h}(\mathrm{p}=0.0163)$, and $42.4 \pm 5.2 \%$ and $30.2 \pm 2.1 \%$ at $8 \mathrm{~h}(\mathrm{p}=0.0218)$, in COC1 and $\mathrm{COC1/DDP}$ cells, respectively (Figures $1(\mathrm{~b})$ and $1(\mathrm{~d})$ ). These data indicated that nsEP induced early and delayed cellular damage.

In the neutral assay, comets appeared only at $8 \mathrm{~h}$, demonstrating SSB at $2 \mathrm{~h}$ and DSB at $8 \mathrm{~h}$. The percentage of cometformed cells was increased in both cell lines $(p=0.0013$, $\mathrm{p}=0.0042$ ), and the value in COC1 cells was higher than that in COC1/DDP cells $(20.0 \pm 3.3 \%$ versus $11.1 \pm 2.5 \%, \mathrm{p}=0.0487)$ (Figures 1(c) and 1(e)).

nsEP can directly induce reversibly transient externalization of phosphatidylserine, causing a false positive in identifying apoptotic cells $[6,19]$. Therefore, apoptosis was detected $\geq 2 \mathrm{~h}$ after treatments to decrease experimental errors. Apoptosis was analyzed at 2 and $8 \mathrm{~h}$, considering the temporal pattern of cell death and DNA damage. A percentage of $<5 \%$ demonstrated a lack of apoptosis at $2 \mathrm{~h}$. The apoptotic percentage was increased in both cell lines at $8 \mathrm{~h}(\mathrm{p}<0.0001$, $\mathrm{p}<0.0001)$, with a higher value in COC1 cells $(27.6 \pm 1.0 \%$ versus $20.6 \pm 0.5 \%$ for early apoptosis, $\mathrm{p}=0.0162 ; 33.5 \pm 0.8 \%$ versus $23.5 \pm 3.1 \%$ for total apoptosis, $\mathrm{p}=0.0355$ ) (Figures 2 (a) and $2(\mathrm{~b}))$. The activity of caspase- 3 was increased in both cell lines at $8 \mathrm{~h}(\mathrm{p}<0.0001, \mathrm{p}<0.0001)$ (Figure 2(c)). HMGB1 was detected to determine the cell-death mode, since flow cytometry cannot distinguish late apoptotic cells from those membrane-intact necrotic cells [14]. The HMGB1 level was not increased after nsEP exposure $(\mathrm{p}=0.2594, \mathrm{p}=0.4142)$ (Figure 2(d)). These findings demonstrated that cell death at $8 \mathrm{~h}$ was due to apoptosis. 


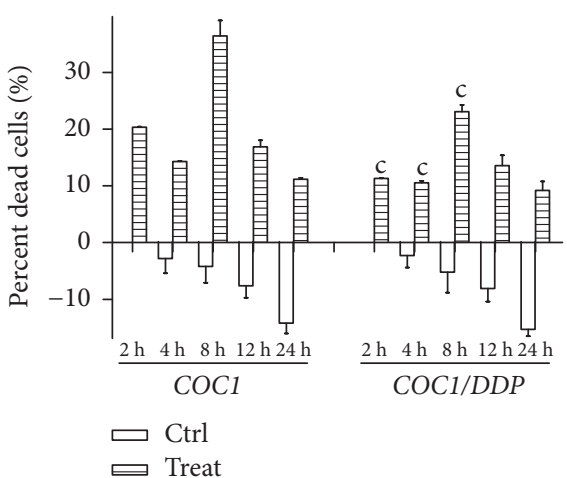

(a)

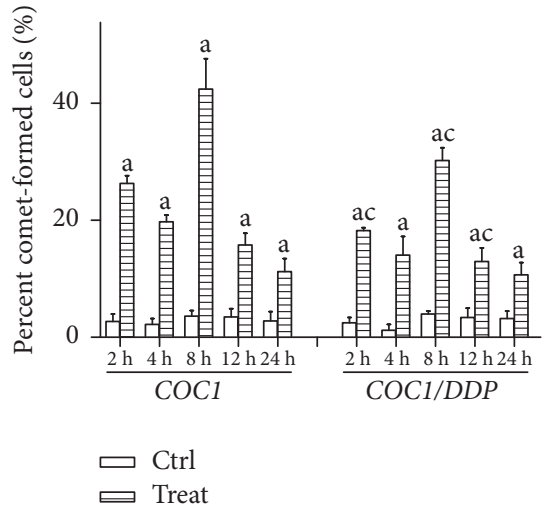

(b)

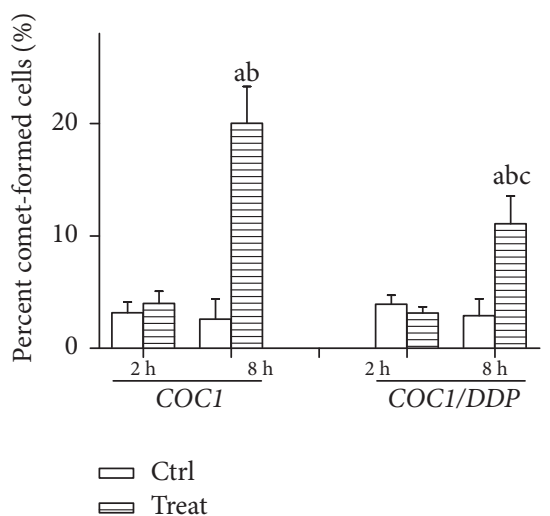

(c)
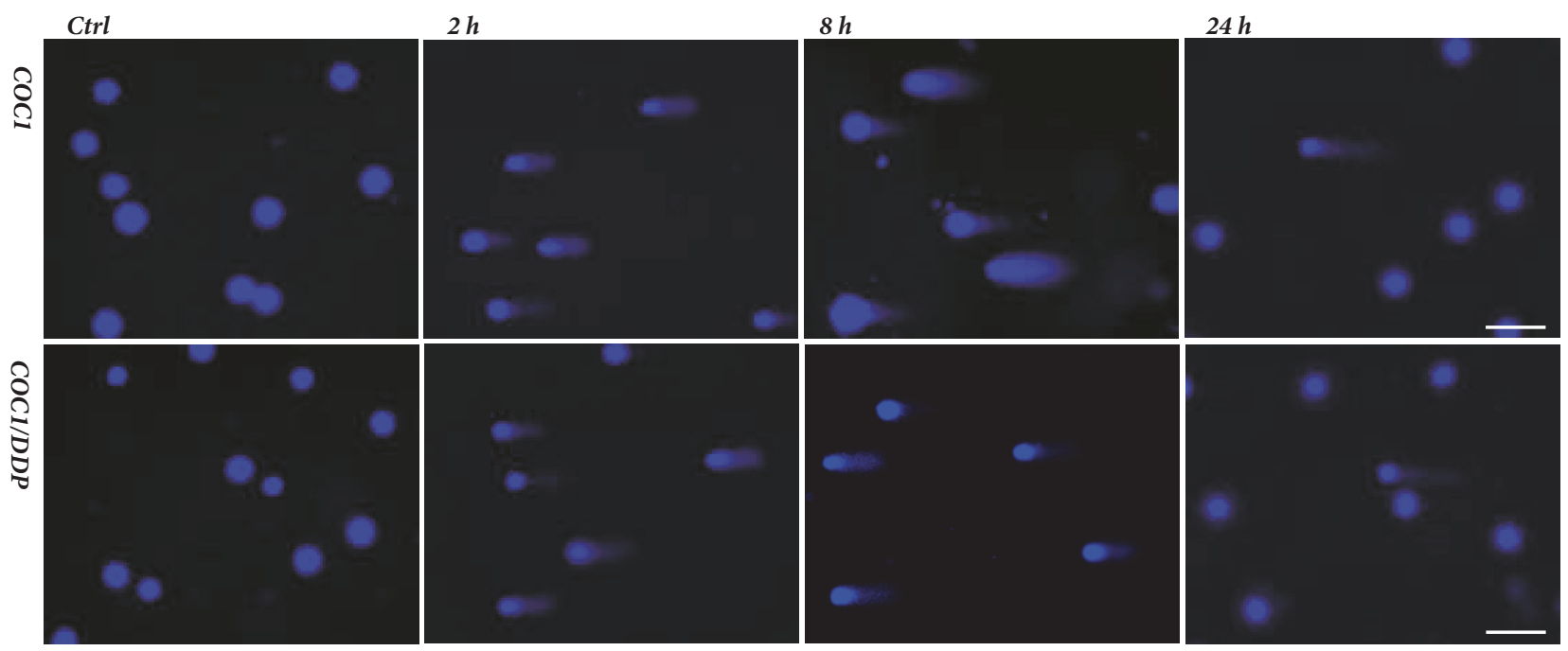

(d)
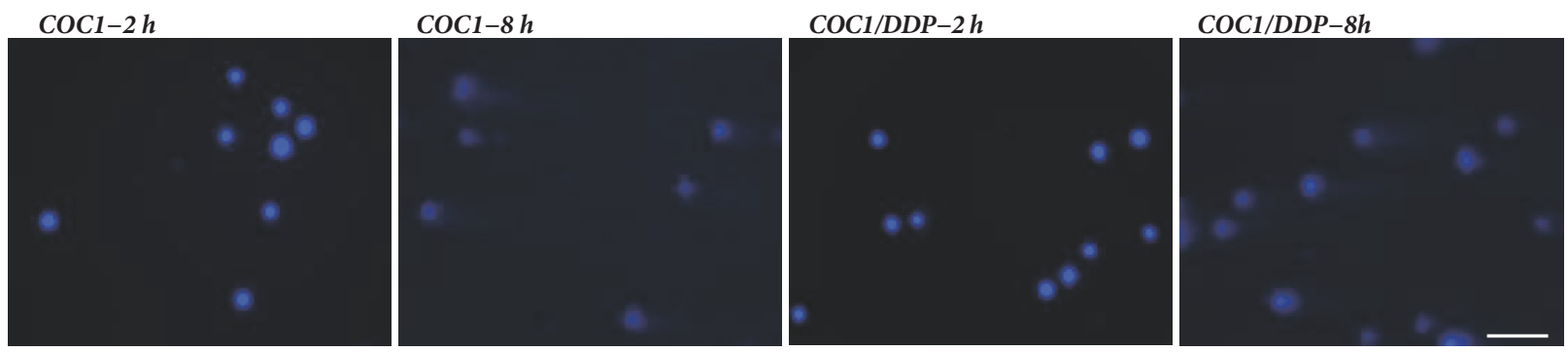

(e)

FIGURE 1: Percentages of dead cells $(a)$ and of comet-formed cells in the alkaline assay $(b)$ after nsEP treatments: the negative death fraction demonstrated proliferation of control cells; two peak levels were detected at 2 and $8 \mathrm{~h}$, with the highest value at $8 \mathrm{~h}$; the value in COC1 cells was higher than that in COC1/DDP cells. Percentage of comet-formed cells in the neutral assay (c): the value was increased at $8 \mathrm{~h}$. Images under the alkaline assay $(d)$ : more comets were observed at 2 and $8 \mathrm{~h}$ in both cell lines; few comets emerged at $24 \mathrm{~h}$, indicating repair. Images under the neutral assay $(e)$ : comets appeared at $8 \mathrm{~h}$, demonstrating single-strand break at $2 \mathrm{~h}$ and double-strand break at $8 \mathrm{~h}$. Data were mean \pm standard deviation for 3 independent experiments. The scale bar was $50 \mu \mathrm{m}$; (a) versus control, $\mathrm{p}<0.05$; (b) versus $2 \mathrm{~h}, \mathrm{p}<0.05$; and (c) versus $\mathrm{COC} 1$ at the same time point, $\mathrm{p}<0.05$.

The first peak of cell death and DNA damage occurred $2 \mathrm{~h}$ after nsEP exposure. The comet assay showed that DNA damage was SSB. Most SSB can be repaired; certain SSB would evolve into DSB and eventually resulted in cell death via the apoptosis pathway (a programmed process required several hours) [20]. These suggested that cell death at $2 \mathrm{~h}$ may not be due to apoptosis. This deduction was supported by alterations of the apoptotic percentage and of caspase- 3 

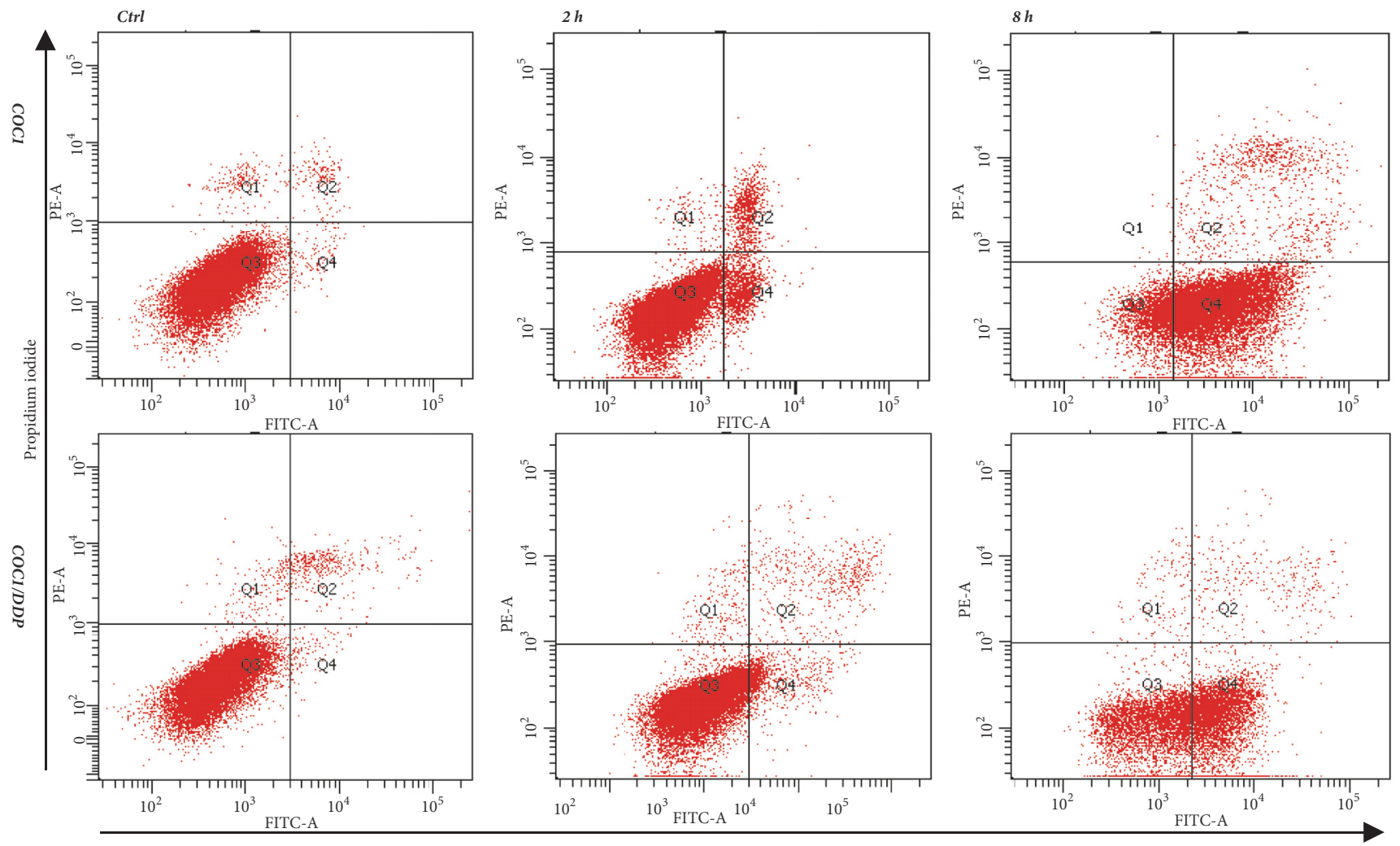

(a)

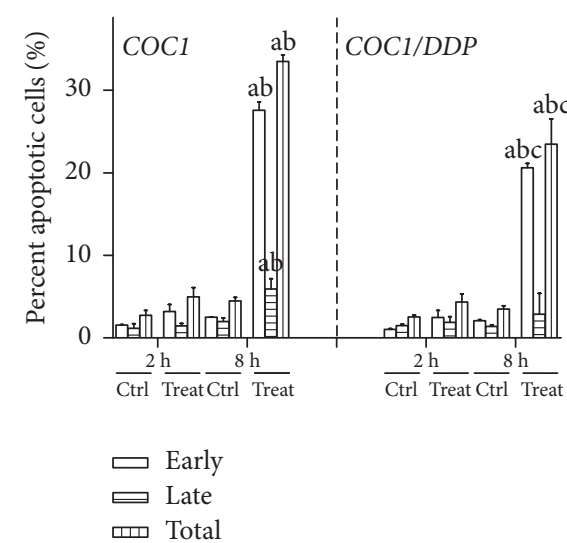

(b)

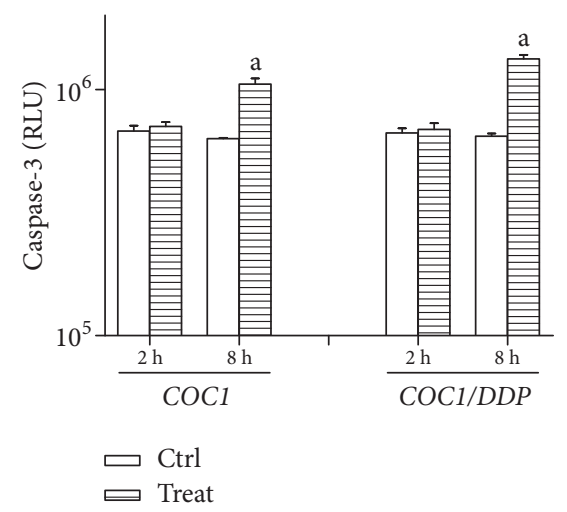

(c)

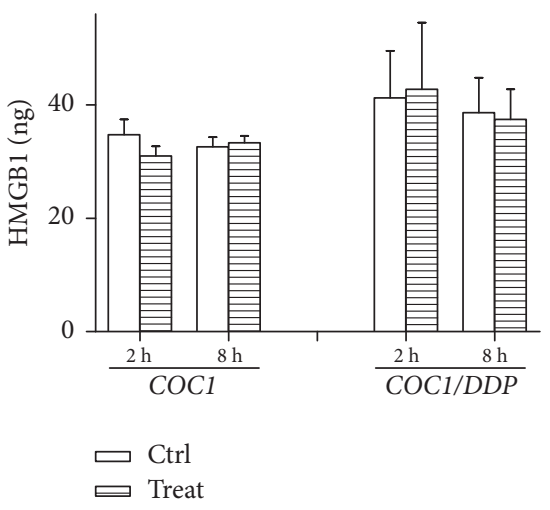

(d)

FIGURE 2: Apoptosis detected with flow cytometry after 2 and $8 \mathrm{~h}(a, b)$ : Q4 represented early apoptotic cells, and Q2 represented late apoptotic cells; a higher apoptotic percentage was detected at $8 \mathrm{~h}$, and the value in $\mathrm{COCl}$ cells was higher than that in COC1/DDP cells. Activity of caspase-3 (c): relative light unit (RLU) reflected the enzymatic level; a higher level was noted at $8 \mathrm{~h}$. HMGB1 level (d): no increase was detected. Data were mean \pm standard deviation for 3 independent experiments. (a) versus control, $\mathrm{p}<0.05$; (b) versus $2 \mathrm{~h}, \mathrm{p}<0.05$; (c) versus $\mathrm{COC} 1$ at the same time point, $\mathrm{p}<0.05$.

activity. Theoretical calculations indicated that the evoked potential in the cellular membrane increased with widening the pulse duration and elevating the strength [4]. Thus, nsEP applied in this study can evoke a potential of about $0.5 \mathrm{~V}$ in the cellular membrane $(0.2 \mathrm{~V}$ was the lowest critical potential required to create membrane pores) [3, 4]. An amount of unrepairable membrane pores would lead to cell lysis [21]. Similar findings were reported in U937 cells: early cell death was detected $1-2 \mathrm{~h}$ after nsEP exposure, which resulted from the rupture of plasmic membrane [22]. These results were contrary to the prevalent verdict that nsEP caused repairable nanopores $[3,5,7,19]$. Previous trials were commonly performed under a single pulse. The present data indicated that membrane pores displayed distinct behaviors under multiple pulses. Continuous pulses can delay the closure of pores and can create new pores, leading to expansion and amalgamation of pores, and ultimately formed large-size pores rupturing the cellular membrane. Pakhomova et al. attributed early 


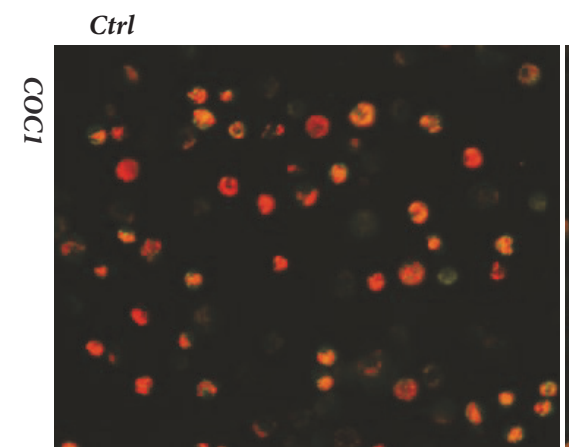

$2 h$
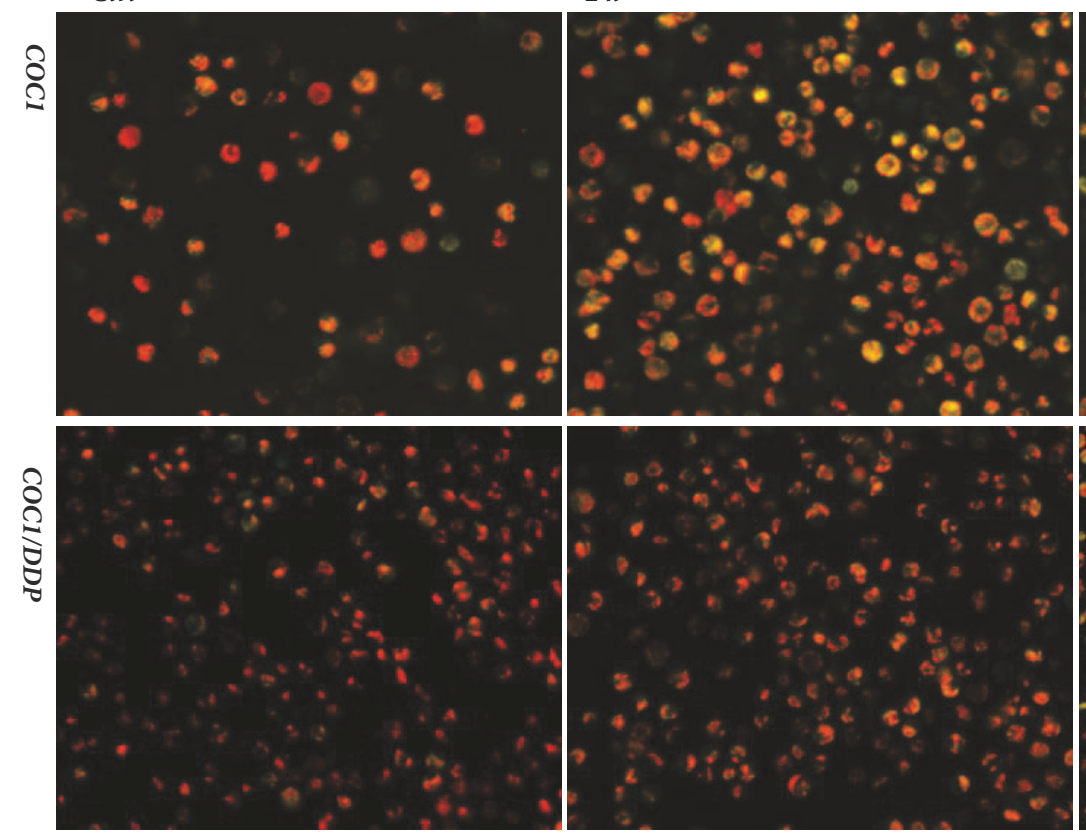

(a)

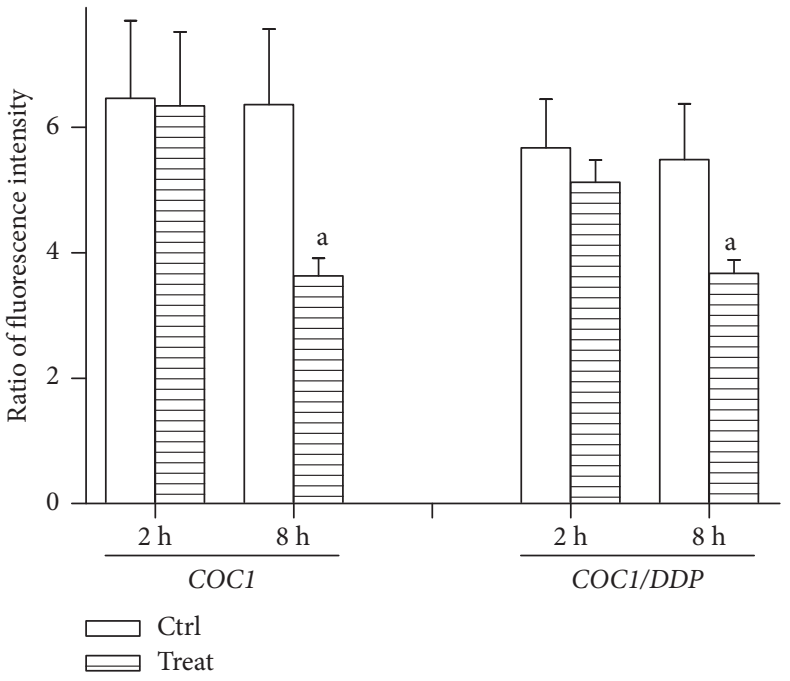

(b)
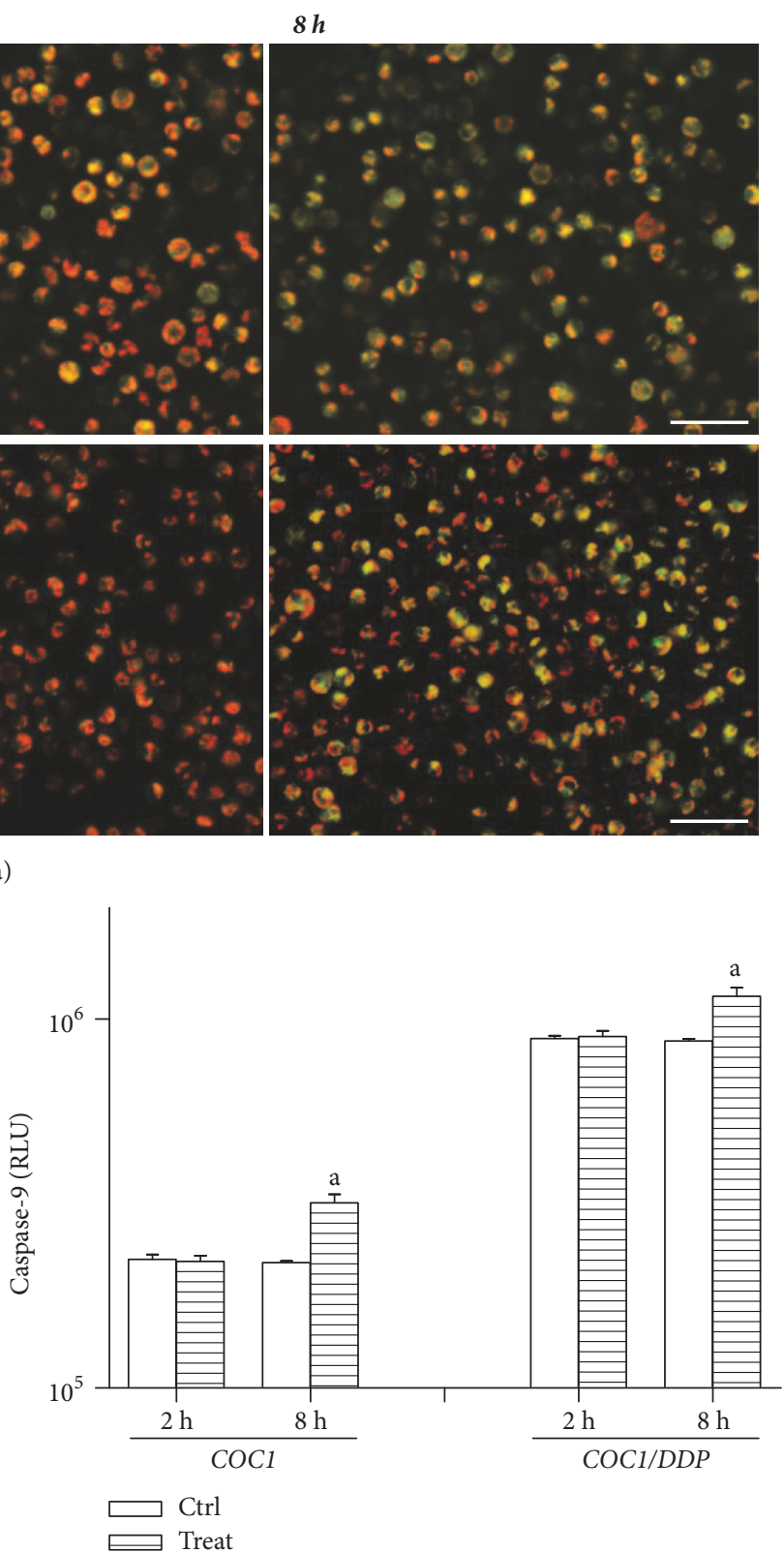

(c)

FIGURE 3: Mitochondrial membrane potential detected with the JC-1 assay. Images under fluorescence microscopy (a): green fluorescence was due to the monomer of JC- 1 and the number of green cells was increased at $8 \mathrm{~h}$, indicating collapse of the potential. The membrane potential qualified with the ratio of fluorescence intensity $(b)$ : the potential was decreased at $8 \mathrm{~h}$. Activity of caspase- 9 at 2 and $8 \mathrm{~h}(c):$ relative light unit (RLU) reflected the enzymatic level; the enzymatic activation was detected at $8 \mathrm{~h}$. Data were mean \pm standard deviation for 3 independent experiments. The scale bar was $50 \mu \mathrm{m}$; (a) versus control, $\mathrm{p}<0.05$.

cell death to necrosis for lack of caspase-3 activation [22]. Necrosis was a nonprogrammed death mode and was trigged by intracellular damage accompanied with the release of HMGB1 [23]. The HMGB1 level was not increased in the present study. These data demonstrated that early cell death was mainly due to cell lysis. Chemoresistant cells usually had apoptotic deficiency, and the induction of nonapoptotic death can be an alternative therapy $[2,8]$. These suggested that nsEP may be a modality against chemoresistant cancer cells.
Romeo et al. observed the DNA electrophoretic pattern in Jurkat cells [24]. DNA migration appeared immediately after single nsEP exposure $(60 \mathrm{~ns}, 25 \mathrm{kV} / \mathrm{cm})$, deteriorated at $20 \mathrm{~min}$, and returned to the baseline level at $1 \mathrm{~h}$; these indicated that nsEP can directly affect the nucleus and that the maximal effect emerged after a certain interval. A strength of $6 \mathrm{kV} / \mathrm{cm}$ evoked a potential of $1.98 \mathrm{~V}$ in the nucleoplasm [4]. A higher strength with multiple pulses was employed in this study, thereby evoking a longer-lasted higher nucleoplasmic potential $(\approx 3.2 \mathrm{~V})$. Additionally, the temperature rise in the 
cell suspension was $<1^{\circ} \mathrm{C}$, demonstrating no involvement of thermal effects. Therefore, SSB at $2 \mathrm{~h}$ may result from directly electric effects.

The second peak level of cell death and DNA damage was detected after $8 \mathrm{~h}$. The apoptotic percentage was increased and approached to the cell-death percentage; caspase- 3 was activated, and there was no increase of the HMGB1 level. The time span from SSB to apoptosis commonly was several hours [20]. A long interval between nsEP treatments and the activation of caspase-3 was consistent with the theoretical simulations of Song et al., where the caspase-3 level elevated after $5 \mathrm{~h}$ in mitochondrial apoptosis due to nsEP [25]. These data manifested that cell death at $8 \mathrm{~h}$ was due to apoptosis.

3.2. Mitochondrial Damage Was Observed at $8 \mathrm{~h}$. The JC-1 ratio was decreased at $8 \mathrm{~h}$ and no variation was observed at $2 \mathrm{~h}$, in both COC1 and COC1/DDP cells ( $\mathrm{p}=0.0074, \mathrm{p}=0.0158$ ) (Figures 3(a) and 3(b)). The level of activated caspase-9 was increased in both cell lines at $8 \mathrm{~h}(\mathrm{p}<0.0001, \mathrm{p}<0.0001)$ (Figure 3(c)). These data demonstrated the occurrence of mitochondrial damage.

A strength of $6 \mathrm{kV} / \mathrm{cm}$ can evoke a potential of $1.17 \mathrm{~V}$ in the nucleoplasm [4]. Thus, nsEP applied in this study can evoke a higher cytoplasmic potential $(\approx 1.9 \mathrm{~V})$ to impair mitochondria, initiating apoptosis $[3,26]$. The collapse of mitochondrial membrane potential and activation of caspase9 demonstrated mitochondrial insults and mitochondriadependent apoptosis. This result accorded with the prevalent verdict that nsEP deactivated cells via apoptosis $[6,7,19]$. A translocation of apoptosis inducing factor from mitochondria into the nucleus led to cleavage of DNA, thereby resulting in DSB [27]. Because DNA break mainly resulted from apoptosis, the gap between the percentage of comet-formed cells and that of dead/apoptotic cells was relatively narrow.

3.3. Potential Therapeutic Applications. These two phases of cell death had distinctly therapeutic implications. The first phase was mainly due to cell lysis, which can be used to necrotize cancer tissues directly. The second phase was due to apoptosis, thereby being a strategy to enhance the action of an apoptotic therapy (e.g., chemotherapy). Therefore, nsEP can deactivate resistant cells via multiple pathways. This was an advantage since chemoresistance resulted from many overlapped mechanisms-the induction of a sequence of cell death can lead to synergism to improve the therapeutic efficacy. The temporal pattern of cell death was a reference to set the interval for administrating other treatments [21].

A less percentage of dead/comet-formed cells after $8 \mathrm{~h}$ demonstrated the cellular repair. A similar result was observed in insonated cells: the proliferation capacity was improved in certain subpopulations causing compensational effects, which was related to the heterogeneity of cancer cells [28-30]. Cells with a higher repair capacity had a higher compensation capacity. This may play a part in the lower toxicity noted in COC1/DDP cells and should be explored to formulate a protocol to set the interval between therapeutic courses.

The evoked potential in a subcellular unit was determined by nsEP applied (strength and the pulse duration), electric property of contents (conductivity and permittivity), and absolute and relative sizes of a cell [19]. Thus, for a specific cancer type, an expected potential within cancer cells can be realized by modulating the strength and pulse duration, improving the therapeutic effect. nsEP caused lower cytotoxicity in chemoresistant cells; underlying mechanisms should be explored in follow trials.

\section{Conclusion}

nsEP induced an early phase of cell death and caused SSB. nsEP induced apoptosis leading to a late phase of cell death, which related to mitochondria insults. The temporal pattern of DNA break and cell death may have distinct implications to treatments of resistant ovarian cancers.

\section{Data Availability}

The data used to support the findings of this study are included within the article.

\section{Conflicts of Interest}

The authors declare no conflicts of interest.

\section{Acknowledgments}

This work was supported with a grant from the Natural Science Foundation of China (31470822).

\section{References}

[1] N. C. Kampan, M. T. Madondo, O. M. McNally, M. Quinn, and M. Plebanski, "Paclitaxel and its evolving role in the management of ovarian cancer," BioMed Research International, vol. 2015, Article ID 413076, 2015.

[2] T. Yu, L. Luo, and L. Wang, "Ultrasound as a cancer chemotherapy sensitizer: the gap between laboratory and bedside," Expert Opinion on Drug Delivery, vol. 13, no. 1, pp. 37-47, 2016.

[3] J. C. Weaver, "Electroporation of cells and tissues," IEEE Transactions on Plasma Science, vol. 28, no. 1, pp. 24-33, 2000.

[4] L. Linghu, Y. Tan, Y. Lou, L. Hu, H. Yang, and T. Yu, "Nanosecond electric pulses induce DNA breaks in cisplatin-sensitive and -resistant human ovarian cancer cells," Biochemical and Biophysical Research Communications, vol. 430, no. 2, pp. 695699, 2013.

[5] L. Chopinet and M. P. Rols, "Nanosecond electric pulses: a minireview of the present state of the art," Bioelectrochemistry, vol. 103, pp. 2-6, 2015.

[6] T. Batista Napotnik, M. Reberšek, P. T. Vernier, B. Mali, and D. Miklavčič, "Effects of high voltage nanosecond electric pulses on eucaryotic cells (in vitro): a systematic review," Bioelectrochemistry, vol. 110, pp. 1-12, 2016.

[7] K. H. Schoenbach, "From the basic science of biological effects of ultrashort electrical pulses to medical therapies," Bioelectromagnetics, vol. 39, no. 4, pp. 257-276, 2018.

[8] K. Mäbert, M. Cojoc, C. Peitzsch, I. Kurth, S. Souchelnytskyi, and A. Dubrovska, "Cancer biomarker discovery: current status and future perspectives," International Journal of Radiation Biology, vol. 90, no. 8, pp. 659-677, 2014. 
[9] S. Murata, C. Zhang, N. Finch, K. Zhang, L. Campo, and E.K. Breuer, "Predictors and modulators of synthetic lethality: an update on PARP inhibitors and personalized medicine," BioMed Research International, vol. 2016, Article ID 2346585, 2016.

[10] T. Yu, Y. Yang, J. Zhang, H. He, and X. Ren, "Circumvention of cisplatin resistance in ovarian cancer by combination of cyclosporin A and low-intensity ultrasound," European Journal of Pharmaceutics and Biopharmaceutics, vol. 91, pp. 103-110, 2015.

[11] M. J. Stoddart, "WST-8 analysis of cell viability during osteogenesis of human mesenchymal stem cells," Methods in Molecular Biology, vol. 740, pp. 21-25, 2011.

[12] P. L. Olive and J. P. Banáth, "The comet assay: a method to measure DNA damage in individual cells," Nature Protocols, vol. 1, no. 1, pp. 23-29, 2006.

[13] H. He, H. Huang, and T. Yu, "Detection of DNA damage in sonochemotherapy against cisplatin-resistant human ovarian cancer cells using the modified comet assay," International Journal of Radiation Biology, vol. 90, no. 10, pp. 897-902, 2014.

[14] M. L. Cuestas, A. Sosnik, and V. L. Mathet, "Poloxamines display a multiple inhibitory activity of ATP-binding cassette (ABC) transporters in cancer cell lines," Molecular Pharmaceutics, vol. 8, no. 4, pp. 1152-1164, 2011.

[15] M. M. Brooks, S. Neelam, R. Fudala, I. Gryczynski, and P. R. Cammarata, "Lenticular mitoprotection. Part A: monitoring mitochondrial depolarization with JC-1 and artifactual fluorescence by the glycogen synthase kinase-3 $\beta$ inhibitor, SB216763," Molecular Vision, vol. 19, pp. 1406-1412, 2013.

[16] A. Raucci, R. Palumbo, and M. E. Bianchi, "HMGB1: a signal of necrosis," Autoimmunity, vol. 40, no. 4, pp. 285-289, 2007.

[17] Y. Mi, S. Rui, C. Li et al., "Multi-parametric study of temperature and thermal damage of tumor exposed to high-frequency nanosecond-pulsed electric fields based on finite element simulation," Medical \& Biological Engineering \& Computing, vol. 55, no. 7, pp. 1109-1122, 2017.

[18] W. Ma, Y. Zhang, X. Zheng, and T. Yu, "Biphasically modulating the activity of carboxypeptidase G2 with ultrasound," Cellular Physiology and Biochemistry, vol. 42, no. 4, pp. 1614-1622, 2017.

[19] R. P. Joshi and K. H. Schoenbach, "Bioelectric effects of intense ultrashort pulses," Critical Reviews in Biomedical Engineering, vol. 38, no. 3, pp. 255-304, 2010.

[20] N. J. Curtin, "DNA repair dysregulation from cancer driver to therapeutic target," Nature Reviews Cancer, vol. 12, no. 12, pp. 801-817, 2012.

[21] Y. Zhang, J. Li, and T. Yu, "Pharmacokinetic profiles of cancer sonochemotherapy," Expert Opinion on Drug Delivery, vol. 14, no. 6, pp. 745-753, 2017.

[22] O. N. Pakhomova, B. W. Gregory, I. Semenov, and A. G. Pakhomov, "Two modes of cell death caused by exposure to nanosecond pulsed electric field," PLoS ONE, vol. 8, no. 7, Article ID e70278, 2013.

[23] Y. Yu, D. Tang, and R. Kang, "Oxidative stress-mediated HMGB1 biology," Frontiers in Physiology, vol. 6, Article ID 93, 2015.

[24] S. Romeo, L. Zeni, M. Sarti et al., "DNA electrophoretic migration patterns change after exposure of jurkat cells to a single intense nanosecond electric pulse," PLoS ONE, vol. 6, no. 12, Article ID e28419, 2011.

[25] J. Song, R. P. Joshi, and S. J. Beebe, "Cellular apoptosis by nanosecond, high-intensity electric pulses: model evaluation of the pulsing threshold and extrinsic pathway," Bioelectrochemistry, vol. 79, no. 2, pp. 179-186, 2010.
[26] A. Burlaka, M. Selyuk, M. Gafurov, S. Lukin, V. Potaskalova, and E. Sidorik, "Changes in mitochondrial functioning with electromagnetic radiation of ultra high frequency as revealed by electron paramagnetic resonance methods," International Journal of Radiation Biology, vol. 90, no. 5, pp. 357-362, 2014.

[27] S. Orrenius, V. Gogvadze, and B. Zhivotovsky, "Calcium and mitochondria in the regulation of cell death," Biochemical and Biophysical Research Communications, vol. 460, no. 1, pp. 72-81, 2015.

[28] T. Yu, J. Bai, K. Hu, and Z. Wang, "Biological effects of ultrasound exposure on adriamycin-resistant and cisplatinresistant human ovarian carcinoma cell lines in vitro," Ultrasonics Sonochemistry, vol. 11, no. 2, pp. 89-94, 2004.

[29] Y. Zhang, L. Luo, X. Zheng, and T. Yu, "An advanced orthotopic ovarian cancer model in mice for therapeutic trials," BioMed Research International, vol. 2016, Article ID 2585787, 2016.

[30] P. T. Kroeger and R. Drapkin, "Pathogenesis and heterogeneity of ovarian cancer," Current Opinion in Obstetrics and Gynecology, vol. 29, no. 1, pp. 26-34, 2017. 


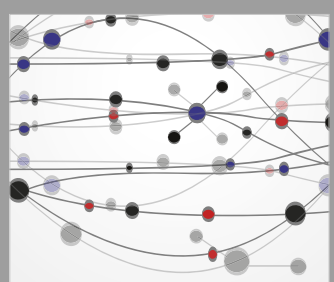

The Scientific World Journal
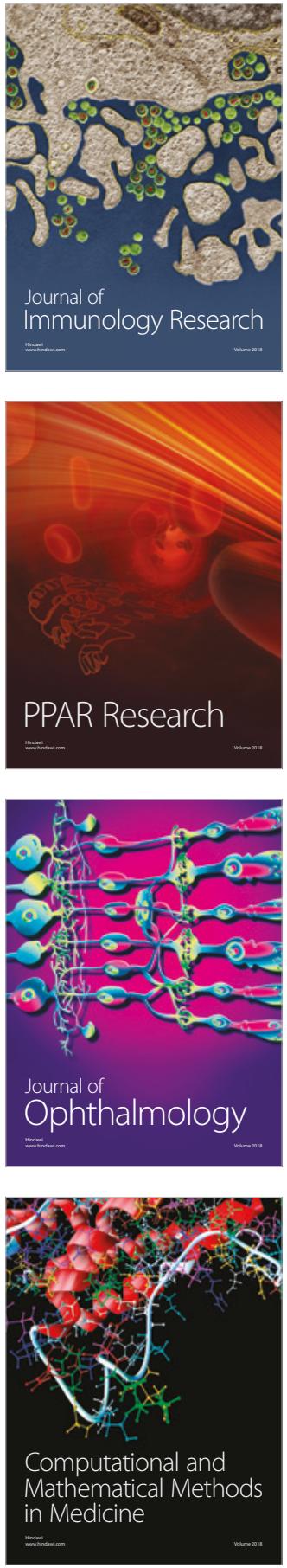

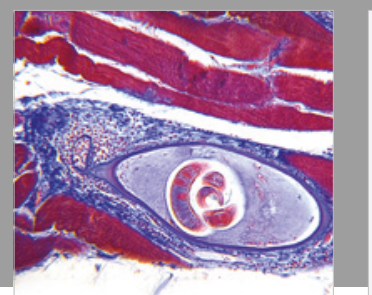

Gastroenterology Research and Practice

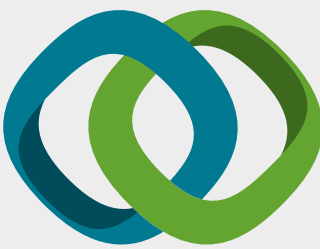

\section{Hindawi}

Submit your manuscripts at

www.hindawi.com
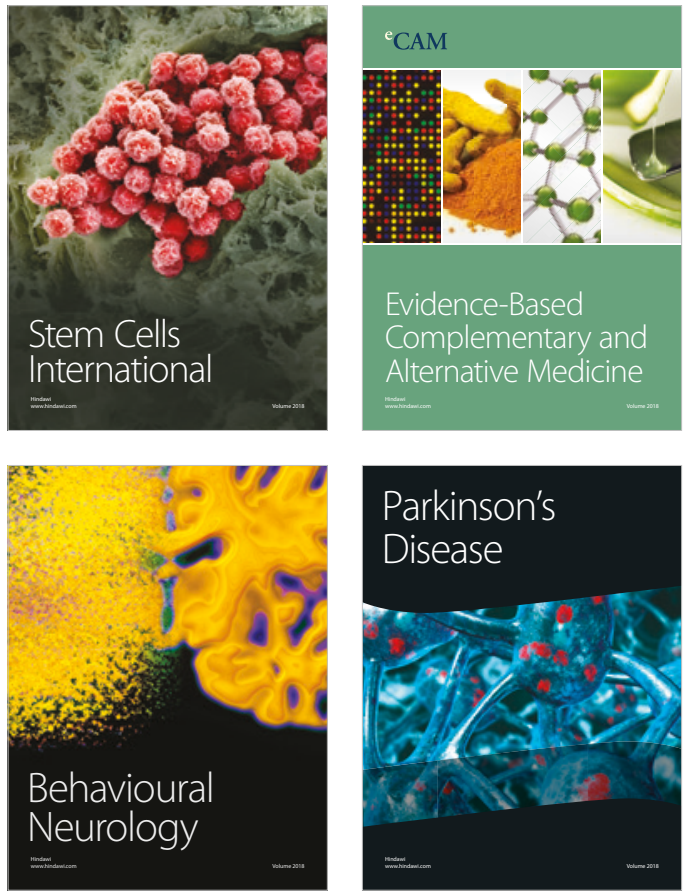

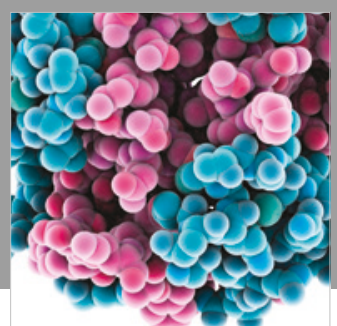

ournal of

Diabetes Research

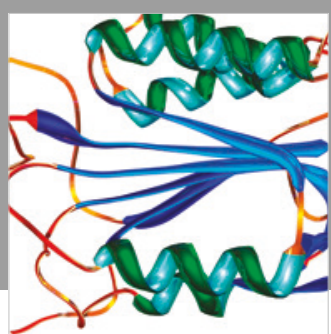

Disease Markers
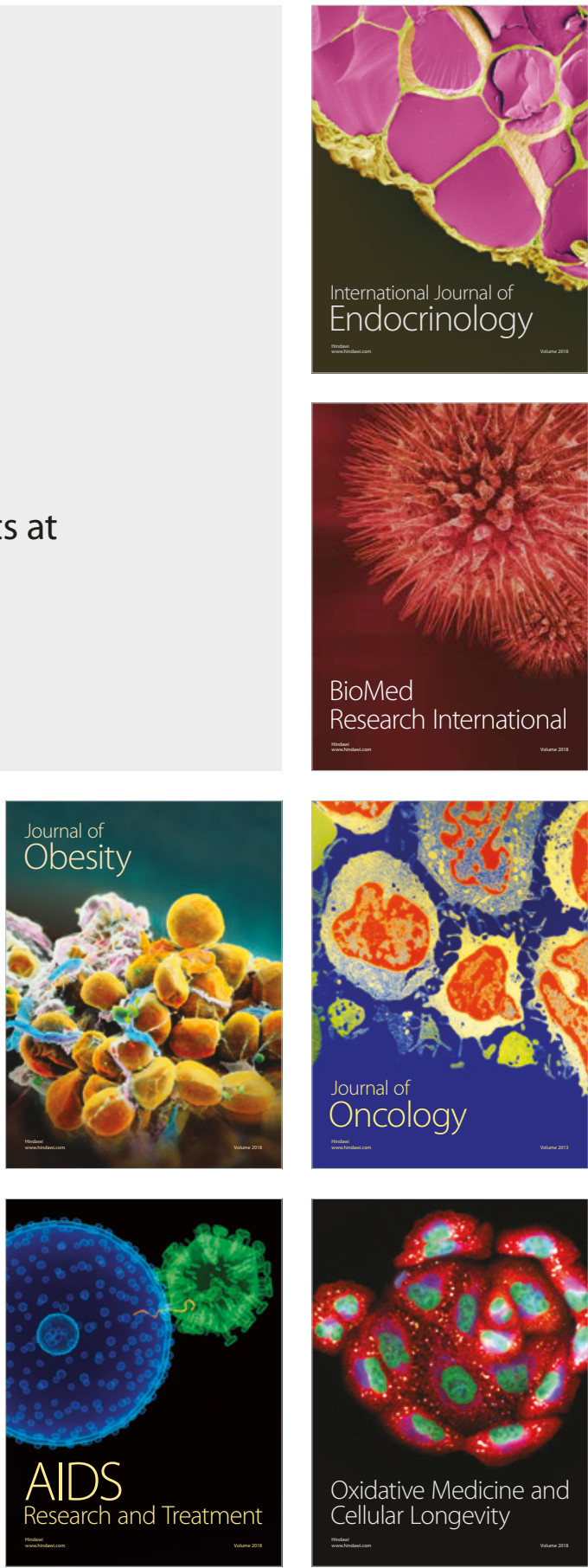